\title{
CHARACTERISTICS OF THE MICROSCOPIC STRUCTURE OF COAT HAIR CUTIQUE OF CAMEROON BREED (CAPRA AEGAGRUS HIRCUS)
}

\section{Pikhtirova Alina ${ }^{1}$ \\ Ivchenko Viktoria ${ }^{2}$}

DOI: https://doi.org/10.30525/978-9934-571-89-3_89

Microscopic and morphometric indices of animals hair of different species have specific features important for identifying a particular species of animal $[1 ; 4$; 7, p. 13; 9, p. 2].

Despite the fact that at present, the latest scientific methods for determining the species of animals at the molecular level are used, morphological methods for determining the species of animals by the characteristics of anatomical structures, namely the microstructure of the hair, remain relevant $[5$, p. $27 ; 9$, p. $4 ; 10]$.

The skin of mammals is covered with hair. It covers almost the entire surface of the body, protecting the body from cooling, and the skin - from mechanical damage and sunlight. Hair consists of three layers - core, peel and cuticles. The superficial layer of hair - the cuticle - consists of one series of horny scales, which tile-like cover the cortical substance $[1-3 ; 8 ; 9$, p. 7].

\footnotetext{
${ }^{1}$ Sumy National Agrarian University, Ukraine

${ }^{2}$ Sumy National Agrarian University, Ukraine
} 
One of the most modern and more precise laboratory methods are scanning electron microscopy, which allows you to differentiate biological objects at the microscopic level $[4 ; 6 ; 7$, p. 14; 10]. Therefore, the purpose of our work was to investigate the microstructure of the surface hair samples of the Cameroonian goat breed (Capra aegagrus hircus) and identify the characteristic features of the microscopic structure inherent in the test animal species.

The research was carried out in the laboratory of electron microscopy of the Sumy National Agrarian University. Preparation of samples for the study included the following steps: selection of biological material; degreasing (96\% alcohol); drawing samples on the table; silver dusting using VUP and placing in a chamber of raster electron microscope REM-106I (Selmi).

For this purpose, samples of hair covering 5 goats in the region of the middle third of the spine and middle third of the neck were selected. The microstructure of the hair surface was investigated using a raster electron microscope REM-106I in the range of magnifications from 500 to 1500 times.

The morphometric characteristics of the cuticle were described by REM images using the Digimiser 4.0 digital image analysis program. The following parameters [1] were investigated: the thickness and shape of the hair, the frequency of the location of the scales (as the average number of scales along the line at $100 \mu \mathrm{m}$ along the length of the hair), the transverse dimension of the widest part of the scales. The used program allowed to make a statistical calculation of the average minimum and maximum values of the studied parameters (Figure 1).

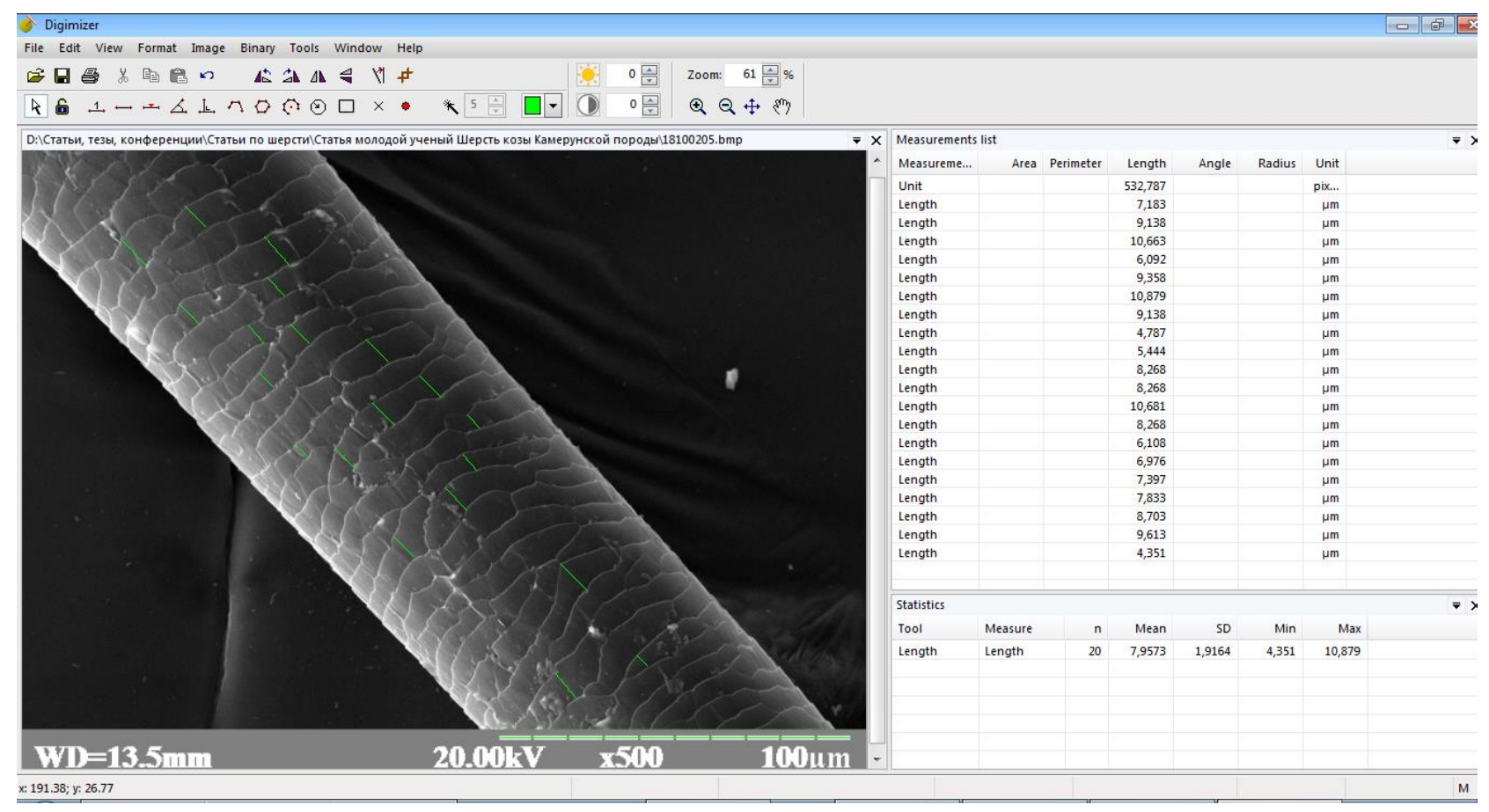

Figure 1. Investigation of morphometric parameters of hair cuticle Capra aegagrus hircus for digital REM-photos in the program Digimizer 4.0

Research results. As a result of studies found that hair goats selected in the neck and spine has significant differences pattern cuticles, shape and thickness (Figure 2). 


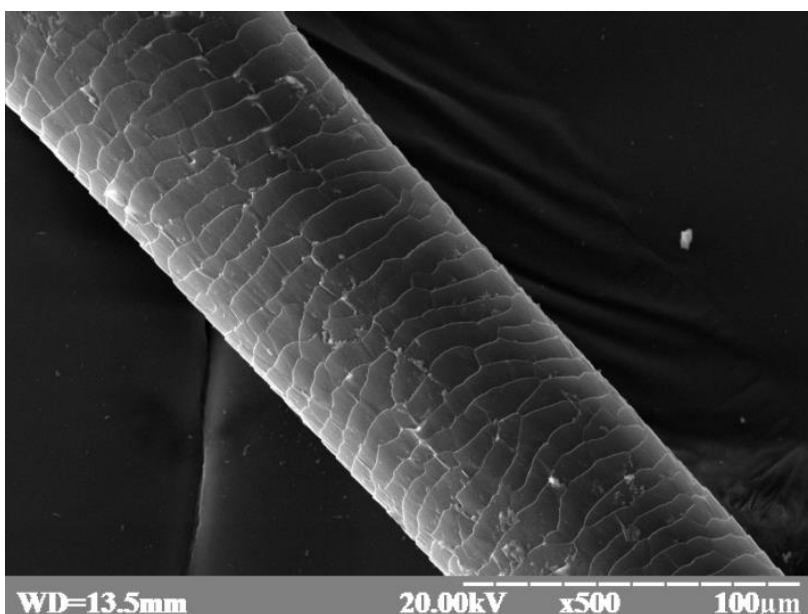

a

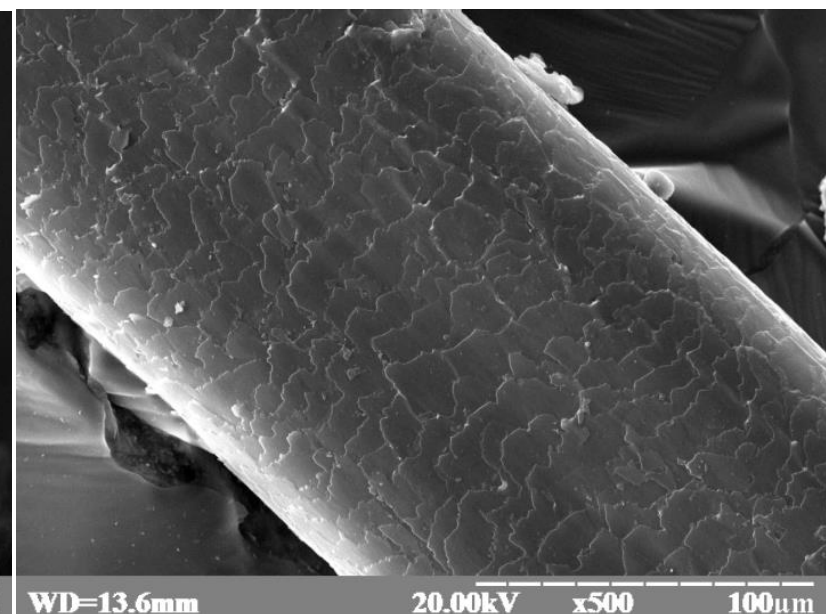

b

Figure 2. Goat hair: a - spine $(74,13 \mu \mathrm{m}), \mathrm{b}-\operatorname{neck}(145,87 \mu \mathrm{m})$

Hair derived from goat spine (Figure 2a) has a cylindrical shape thickness $74,13 \pm 0,24 \mu \mathrm{m}$. Surface cuticle pattern is distinct, has the form of a regular wave formed from solid expanded petals. The number of waves on the hair surface per $100 \mu \mathrm{m}$ in length is 12 . Scales on the surface of the hair slightly different in shape, with sharp edges, tight to the surface of hair, longitudinal direction. The size of the scales (wavelength) varies in the range 4,35-10,88 $\mu \mathrm{m}$.

Hair of Capra aegagrus hircus taken from the neck area (Figure 2b), flattened shape in the thickness 145,87-149,24 $\mu \mathrm{m}$. Surface cuticle pattern is crisp, formed from scales of various sizes with torn edges and has the appearance of an irregular wave. The number of waves on the hair surface per $100 \mu \mathrm{m}$ in length is 10 . Scales on the hair surface vary in shape, don't have clear edges, sometimes loosely adjacent to the surface of the hair, longitudinal direction. The size of the scales (wavelength) varies in the range 4,57-18,72 $\mu \mathrm{m}$.

As a result of the study, it should be noted that the hair of Capra aegagrus hircus, taken from different parts of the body, differs from all the studied parameters: shape, thickness, specific surface pattern of the cuticle, which provides the basis for more detailed research in this direction in order to identify a particular species of animals.

\section{References:}

1. Best Practice Manual for the Microscopic Examination and Comparison of Human and Animal Hair ENFSI-BPM-THG-03. URL: https://ghep-isfg.org/pt-pt/publications-pt/publicacionesenfsi/

2. Bradbury H. J. (1976). The morphology and chemical structure of wool. January. PAC, vol. 46, no. 2-4, pp. 247-253. doi: 10.1351/pac197646020247

3. Chernova O. F., Kirillova I. V. (2013). Hair microstructure of the late quaternary bison from north-east Russia. Proceedings of the Zoological Institute Ras (Proceedings Zin), no. 317 (2), pp. 202-216.

4. David M. Lewis, John A. Rippon (2013). The Structure of Wool. The Coloration of Wool and other Keratin Fibres, pp. 1-42. doi: 10.1002/9781118625118.ch1

5. Feughelman Max (1997). Mechanical Properties and Structure of Alpha-Keratin Fibers, Wool, Human Hair and Related Fibers, UNSW Press, Sydney, 165 p. doi: 10.1177/004051759706700710 
6. Rogers G. E. (1959). Electron microscopy of wool. Journal of Ultrastructure Research, vol. 2, issue 3, pp. 309-330.

7. Salygha Ju. T., Snitynsjkyj V. V. (1999). Elektronna mikroskopija biologhichnykh ob'jektiv [Electronic microscopy of biological objects]. Lviv, 152 p. (in Ukranian)

8. Spasskaya N. N., Chernova O. F., Ibraev M. V. (2012). Microstructural characteristics of hair of pleistocene mummy of "Bilibino horse" Equus sp. Moscow University Biological Sciences Bulletin, vol. 67 (1), pp. 36-41. doi: 10.3103/S0096392512010075

9. Teerink B. J. (1991). Hair of west European mammals. Cambridge university press, New York, $224 \mathrm{p}$.

10. Wortmann F.-J. (2009). The structure and properties of wool and hair fibres. University of Manchester, UK, pp. 108-145. doi: 10.1533/9781845697310.1.108 